\title{
Client Characteristics and the Negotiation Tactics of Auditors: Implications for Financial Reporting
}

\author{
Richard C. Hatfield \\ Culverhouse School of Accountancy \\ The University of Alabama \\ Tuscaloosa, AL 35487-0220 \\ (205) 348-2901 \\ rhatfiel@cba.ua.edu \\ Christopher P. Agoglia \\ Department of Accounting \\ Bennett S. LeBow College of Business \\ Drexel University \\ Philadelphia, PA 19104 \\ Maria H. Sanchez \\ Department of Accounting \\ College of Business Administration \\ Rider University
}

April 2007

We would like to thank Helen Brown, Michael Gibbins, Christine Haynes, Bill Kinney, Steve Salterio, participants at the 2005 AAA Annual Meeting, the 2006 Auditing Section Midyear Conference, and the 2006 International Symposium on Audit Research, and workshop participants at Boston College, The University of Alabama, and the University of South Carolina. Data are available upon request. 


\title{
Client Characteristics and the Negotiation Tactics of Auditors: Implications for Financial Reporting
}

\begin{abstract}
Although the financial statements of an organization are considered a product of management, prior research suggests that a company's financial statements may be affected by the negotiation strategy employed by the auditor when resolving audit differences with management. However, little subsequent research has discussed the potential strategies that auditors may employ during the negotiation process. Our study extends the literature by investigating, in a post-SarbanesOxley environment, whether auditors will employ a reciprocity-based strategy for the resolution of audit differences and what client characteristics (client management's negotiating style and client retention risk) will increase the extent to which it is utilized. Further, we explore the potential effect of a reciprocity-based strategy on the quality of the financial statements. Such a strategy involves bringing inconsequential items to management and subsequently waiving these items in an effort to encourage management to be more cooperative in the posting of significant income-decreasing adjustments. The results of experiment 1 indicate that client management's negotiating style and retention risk have an interactive effect on auditors' use of a reciprocity-based strategy. Specifically, auditors are more likely to utilize a reciprocity-based strategy when management's negotiating style is competitive and client retention risk is high. Experiment 2 findings suggest that the auditor's use of reciprocity during negotiation can actually result in more conservative financial statements by helping the auditor manage perceived client pressures to waive or reduce proposed adjustments.
\end{abstract}




\section{INTRODUCTION}

This study examines conditions under which auditors will use a negotiation strategy based on reciprocity that encourages client management to be more cooperative in the posting of significant adjustments (i.e., clearly material or potentially material audit differences) and considers the influence of such a strategy on financial statement quality. While the financial statements of an organization are considered the responsibility of management, negotiations between auditors and their clients regarding the contents of the financial statements are quite common and may affect accounting disclosure (Antle and Nalebuff 1991; Gibbins et al. 2001). Consequently, as Antle and Nalebuff (1991) note, a company's financial statements could be viewed as a product of the joint efforts of the two parties. In addition to the resolution of proposed adjustments, negotiation has an important influence on client relations (Gibbins et al. 2001). Thus, the process of resolving audit differences could affect client retention and satisfaction, as well as the resulting financial statements.

The Rule of Reciprocation states that when an individual receives something of value, that individual has an obligation to reciprocate. In a negotiation setting, the reciprocation rule can promote a collaborative environment where, if one party makes concessions from his/her initial position, the other party is likely to reciprocate with concessions of his/her own (Putnam 1990; Kelly 1997). In the context of auditor-client negotiations, this could involve the auditor bringing inconsequential audit differences (in addition to any significant items) uncovered by the audit team to management's attention and then waiving the inconsequential items. ${ }^{1}$ Sanchez et al. (2007) find that client managers are more agreeable toward posting significant income-decreasing items to the financial statements, and more satisfied with the auditor and the negotiation process, when the

\footnotetext{
${ }^{1}$ Nine national and international firms, in A Framework for Evaluating Process/Transaction-Level Exceptions and Deficiencies (2004), define an inconsequential item as being less than $20 \%$ of the overall annual or interim financial statement materiality (assuming no material qualitative factors), and discussions with partners of a Big 4 firm indicate industry position is that greater than one percent of pretax income would be considered more than inconsequential.
} 
auditor uses a reciprocity-based strategy such as this for resolving audit differences. While prior research suggests that auditors may alter their approach to negotiations depending on the characteristics of the client and that changes to the approach may affect negotiated outcomes (Gibbins et al. 2001; Trotman et al. 2005; Sanchez et al. 2007), little is known about the potential effects of client characteristics on auditor negotiation strategy.

In this study we conduct two experiments to investigate whether, and under what client characteristics, auditors are likely to use a reciprocity-based strategy (experiment 1), as well as the potential effects of such a strategy on the quality of the financial statements (experiment 2). Both experiments use computer-simulations in which auditor participants engage in an interaction with a hypothetical client to resolve audit differences. In experiment 1, participants are first asked to prepare a preliminary list of audit differences for client management based on a set of eight incomedecreasing items (including both significant and inconsequential items) discovered during the audit; any items not on the list are waived by the participant without bringing them to management's attention (i.e., not in view of client management). After providing management with their preliminary lists, participants then determine whether they are willing to waive any of the inconsequential items they brought to the client in an effort to encourage management to be more cooperative in the posting of significant adjustments. A reciprocity-based strategy would involve both i) bringing inconsequential items to client management and ii) later waiving those items in view of the client management. ${ }^{2}$

\footnotetext{
${ }^{2}$ Discussions with 15 audit partners and managers indicate that this preliminary disclosure typically would occur prior to preparation of the summary of unadjusted audit differences required by SAS No. 89, and that inconsequential items disclosed to client management at this point would not need to be included in the summary of unadjusted audit differences presented to the audit committee. It should also be noted that the current regulatory environment (i.e., SAS No. 89 and the Sarbanes-Oxley Act of 2002) does not necessitate that items waived (whether in view of management or not) be communicated to the audit committee if the items are considered inconsequential by the auditor. Additionally, discussions with practicing auditors indicate that both approaches (i.e., disclosure/non-disclosure of inconsequential items to client management) are still available to auditors post Sarbanes-Oxley.
} 
We manipulate key characteristics of the client to determine how these characteristics influence the use of a reciprocity based-strategy. Specifically, we consider whether auditors will increase their use of a reciprocity-based strategy when facing a client manager known to be a difficult (competitive) negotiator, relative to a collaborative negotiator, given that such a strategy can help steer negotiations into a more collaborative environment (Kelly 1997). In addition, we consider auditor participants' negotiation tactics when client retention risk is high (the client is in the process of soliciting bids for next year's audit). Concern for client retention may place greater pressure on the auditor to have client management form/maintain a favorable opinion of the auditor. ${ }^{3}$ Negotiation literature suggests that, in an environment where the client is soliciting bids, the auditor may feel inclined to make concessions knowing that client management is in a relatively strong negotiating position and likely to expect greater concessions during negotiations (e.g., Hornstein 1965; Michner et al. 1975). Since competitive negotiators are more likely to use any bargaining tool at their disposal (e.g., auditor concerns about retention risk), we expect that auditors' strategic response to a competitive versus collaborative client will be greatest when retention risk is high.

The results of experiment 1 indicate that client management's negotiating style and retention risk have an interactive effect on auditors' use of a reciprocity-based strategy (i.e., bringing inconsequential items to management and subsequently waiving them). Specifically, auditors made greater use of a reciprocity-based strategy when confronted with a competitive negotiator and greater client retention risk. Negotiation results from experiment 1 suggest that use of a reciprocitybased strategy may help the auditor cope with management pressures to waive or reduce significant

\footnotetext{
${ }^{3}$ While Sarbanes-Oxley formalizes/mandates the Blue Ribbon Commission recommendation that (for publicly traded companies) the audit committee hires/terminates the audit firm, discussions with multiple partners from large accounting firms suggest that the more formal rule has not diminished management's significant role in evaluating the audit firm and making retention recommendations. Further, a recent survey of audit committee members and other executives finds that controllers/CFOs have the greatest influence (e.g., greater than the audit committee) over issues such as auditor compensation and retention (KPMG 2004).
} 
proposed adjustments and thus has the potential to improve the quality of the financial statements. We conduct a second experiment to more directly explore the influence of a reciprocity-based strategy on the financial statements.

In experiment 2, we examine the impact of a reciprocity-based strategy in a negotiation setting in which the client is a competitive negotiator and retention risk is high. We focus on this setting given the findings of experiment 1 indicating greater use of reciprocity by auditors in such an environment. Participants in experiment 2 are provided with a preliminary list of audit differences (which includes a significant, subjective item) compiled by the audit team and communicated to client management. We manipulate whether a reciprocity-based strategy is employed and ask participants to meet (through a computerized-interaction) with client management to resolve the significant item. Results indicate that auditors' negotiation goals, minimum required adjustment amounts, and counter-offers to the client are greater (i.e., resulting in more conservative financial statements and lower earnings per share figures) when the strategy is employed than when no such strategy is available. Additionally, results of a mediation analysis suggest that the effect of strategy use on the negotiation process is mediated by the auditor's perceived pressure from client management to waive or reduce the significant adjustment. Specifically, use of a reciprocity-based strategy results in a reduction of perceived resistance from the client which, in turn, leads to more successful outcomes for the auditor.

The remainder of this paper is organized as follows. The next section discusses the background and related research and develops the hypotheses. Sections III and IV present the method and results for experiments 1 and 2, respectively. Section V offers conclusions and implications. 


\section{BACKGROUND AND HYPOTHESIS DEVELOPMENT}

Prior research indicates that the characteristics of an adjustment or an engagement can affect the likelihood that the auditor will waive a particular item (e.g., Wright and Wright 1997; Braun 2001; Nelson et al. 2002; Ng and Tan 2003). Prior research also suggests that auditors may alter their approach to negotiation depending on the characteristics of the client (Gibbins et al. 2001; Sanchez et al. 2007). Negotiators may choose to utilize reciprocity during negotiations in an attempt to create social compliance in their counterparts by offering an initial position greater than their ultimate goal. ${ }^{4}$ Our study extends the literature by investigating whether, and under what client characteristics, auditors will utilize a reciprocity-based strategy for the resolution of audit differences, as well as the potential effect on financial reporting.

\section{Auditor-Client Negotiations}

While the management representation letter asserts that management bears responsibility, a company's financial statements can be viewed as a joint effort of both management and the auditor (Antle and Nalebuff 1991). Antle and Nalebuff (1991) suggest that the resulting financial statements depend on the negotiation strategy employed by the auditor. However, little subsequent research has discussed the potential strategies that auditors may employ during the negotiation process. Related research has typically focused on the disposition of proposed audit adjustments with respect to characteristics of the adjustment or the engagement, finding that adjustments are more likely to be waived when, for example: they are immaterial, they are income increasing, the client is small, the audit committee is ineffective, authoritative guidance is lacking, internal controls

\footnotetext{
${ }^{4}$ However, the findings of $\mathrm{Ng}$ and Tan (2003) suggest that auditors do not inflate the dollar amount of proposed adjustments in anticipation of negotiations (i.e., do not employ a reciprocity-based approach in that manner; see also Bame-Aldred and Kida 2007). They posit this is because auditors consider inflated (i.e., inaccurate) dollar amounts on proposed adjustments to be inappropriate and unprofessional under existing auditing standards and guidelines.

Alternatively, if accuracy is essential, auditors could utilize a strategy such as the one we investigate here in which inconsequential (but accurate with regard to dollar amount) adjustments serve as the initial concession required for a reciprocation-based approach.
} 
are strong, and the risk of waiving is low (e.g., Wright and Wright 1997; Braun 2001; Nelson et al. 2000; Ng and Tan 2003; Joe et al. 2005; Brown and Johnstone 2005).

Gibbins et al. (2001) explicitly consider the negotiation process and provide survey evidence regarding negotiation experience of practicing auditors. They find that $67 \%$ of audit partners surveyed enter into negotiations with more than half of their clients and that all partners surveyed enter into negotiations with at least some of their clients. Additionally, the partners believe negotiation is a frequent and vital part of their responsibilities and is part of the service they provide to the client (Gibbins et al. 2001). While auditors are foremost concerned with the final agreement of the client to post any significant proposed audit adjustments, they are generally also concerned with their continuing working relationship with client management. Fostering a good working relationship with clients is important for the conduct of the audit (Shaub 2004; Arel et al. 2005). In addition, the auditor-client relationship may have implications for auditors' ability to retain clients and, to the extent possible under the Sarbanes-Oxley Act of 2002, increase their level of service (and billing) to their clients.

\section{Collaborative Negotiation and Reciprocity-Based Strategies}

The rule of reciprocation has been found in a variety of settings and is pervasive in all societies (Gouldner 1960; Cialdini 2001). The basic tenet of this societal rule is that if someone provides a person with any type of gift or favor, that person is "obligated" to reciprocate. The rule of reciprocity creates an environment, within the negotiation context, which promotes mutual concession. Effective negotiators can rely on reciprocity to create social compliance in their counterpart by offering an initial position greater than their ultimate goal. By making a concession off of the initial position, the negotiator can expect a concession from his/her counterpart. Further, studies have found that relatively small concessions can result in relatively large reciprocations and that those exposed to this strategy did not feel manipulated, but were more satisfied with the 
outcome than when this strategy was not used (Benton et al.1972; Cialdini and Ascani 1976; Miller et al. 1976; and Schindler 1998).

By coming to the negotiation table with a reciprocity-based strategy (e.g., disclosing certain inconsequential items to client management and subsequently conceding them), auditors can help create a collaborative negotiation environment (Kelly 1997). Collaborative negotiation is characterized by concessions and disclosure of information (Putnam 1990). A collaborative approach will likely lead to integrative reciprocity on the part of client management (Olekalns and Smith 2000). Integrative reciprocity implies not only that the auditor's concessions be reciprocated by management, but also that the resulting collaborative environment promotes more satisfaction with the negotiation process and outcome (Benton et al. 1972; Schindler 1998). In the context of auditor-client negotiations over proposed audit adjustments, it may be helpful to achieve some level of collaboration, since client management will be asked to concede to post any significant items in order for the auditor to issue an unqualified opinion on the financial statements. Further, improved client satisfaction with the process/outcome could lead to greater client retention and future billing. While collaborative negotiation is likely to result in mutually beneficial outcomes, competitive negotiation can lead to conflict escalation and win-lose outcomes (Lax and Sebenius 1986). ${ }^{5}$ Competitive (or non-collaborative) negotiation centers on minimizing concessions and concealing information (Putnam 1990). A competitive environment can negatively affect not only the negotiated outcome, but also the relationship between negotiators (Putnam 1990). An approach by the auditor of waiving inconsequential adjustments without disclosing them to management while insisting that significant items (i.e., the only items the client management does see) be posted, will appear less collaborative and will likely lead to a more competitive negotiation environment.

\footnotetext{
${ }^{5}$ A win-lose outcome (or one party victory) occurs when one of the parties gets most or all of what they want at the expense of the other party.
} 
Sanchez et al. (2007) investigate the effect of a reciprocity-based auditor strategy on the resolution of proposed audit adjustments by considering the client side of the negotiation process. They investigate a potential auditor strategy where auditors disclose income-decreasing, inconsequential items to client management. These inconsequential items could be waived by the auditor with or without disclosing them to management. However, this "concession" approach makes the waiving of inconsequential items transparent (i.e., observable concession). Specifically, the auditor brings to the attention of management all the audit differences (both significant and inconsequential) discovered during the audit and, subsequently, waives the inconsequential items. In contrast, a "no-concession" approach occurs when inconsequential items are waived at the workpaper level without disclosing them to client management (i.e., management is only aware of the significant audit differences, which must be booked). This "concession" approach is compliant with the current regulatory environment including SAS No. 89 and Sarbanes-Oxley. ${ }^{6}$ Their findings indicate that, relative to a no-concession approach, client managers were more willing to agree to post significant income-decreasing adjustments when exposed to a concession approach during the negotiation process. This observable concession also resulted in greater client satisfaction and retention. Sanchez et al. (2007) provide additional evidence that auditors perceive this strategy to be both viable and effective for maintaining client satisfaction while encouraging client management cooperation with the posting of significant adjustments. Our study extends their work by considering whether auditors will initiate and employ a similar reciprocity-based strategy and what client characteristics will increase the extent to which it is used.

\footnotetext{
${ }^{6}$ While SAS No. 89 and Sarbanes-Oxley require that unadjusted immaterial misstatements be communicated to the audit committee, they allow inconsequential differences to be waived at the workpaper level without communication to the audit committee. According to footnote 6 of SAS No. 89, "auditors may designate an amount below which misstatements need not be accumulated. Similarly, the summary of uncorrected misstatements included or attached to the representation letter need not include such misstatements." Thus, the waiving of inconsequential misstatements at the workpaper level is allowable under the current regulatory environment, regardless of whether the items are disclosed to management. Further, discussions with numerous audit partners and managers confirm that waiving audit differences that are below the posting threshold (i.e., inconsequential misstatements), without bringing such differences to the attention of management or the audit committee, is not prohibited by either SAS No. 89 or Sarbanes-Oxley.
} 


\section{Client Characteristics and the Negotiation Environment}

Prior research suggests that auditors may alter their approach to negotiations depending on the characteristics of the client (Gibbins et al. 2001; Sanchez et al. 2007). Thus, auditors' use of a reciprocity-based strategy may be affected by certain client characteristics. That is, an auditor would not need to use a reciprocity-based strategy unless the client/negotiation environment warrants it. One characteristic that may affect the negotiation environment is negotiator style (Pruitt and Carnevale 1993). A negotiator's tendency for contentious tactics typically results in competitive, or non-collaborative, environments (e.g., Druckman 1986). In contrast, actions such as information sharing and concession can help promote a more collaborative environment (Putnam 1990).

Discussions with audit partners from Big 4 firms reveal that some client managers are very reluctant to post any adjustments to the financial statements (competitive clients), while others are more open to posting adjustments (collaborative clients). As a collaborative environment is typically in the auditors' best interest, a competitive client manager can present a dilemma for the auditor. Consequently, auditors may be more likely to initiate a reciprocity-based strategy when the client is a competitive negotiator since such a strategy may induce a more collaborative environment (Kelly 1997). The following hypothesis is, therefore, tested:

H1: Auditors will make greater use of a reciprocity-based strategy when dealing with a competitive client than with a collaborative client.

A second client characteristic that may affect the negotiation environment is the relative strength of a negotiator's position (Pruitt and Carnevale 1993). In an audit context, client retention risk may influence the strength of the client management's negotiating position. A client that is soliciting bids for next year's audit would represent a greater risk to client retention than one that is not explicitly considering an auditor change. Although the responsibility for engaging/terminating the auditor ultimately lies with the audit committee (at least for public companies), management 
generally still has considerable input. ${ }^{7}$ Therefore, it could be advantageous to the auditor for management to view them favorably, particularly when a retention decision is imminent. If management is unfavorable toward the auditor, the audit committee is less likely to retain the auditor. Thus, when a client is soliciting bids, client management is likely put in a relatively stronger position than when retention risk is low. The negotiation literature demonstrates that when one of the negotiators has greater (or increased) strength relative to a counterpart, the relatively stronger party is likely to expect greater concessions (Hornstein 1965; Michner et al. 1975). Consequently, auditors may be more likely to use a reciprocity-based strategy when the client is known to be soliciting bids for next year's audit (high retention risk) than when retention risk is low. This leads to the following hypothesis:

H2: Auditors will make greater use of a reciprocity-based strategy when client retention risk is high than when it is low.

The negotiation literature suggests that, when put in a position of relative strength, negotiators known to use contentious tactics are more effective at utilizing (and more willing to utilize) that relative advantage (Pruitt and Carnevale 1993). Therefore, in a setting where the client is a competitive negotiator and the risk of retaining the client is high, the auditor may encounter a particularly tough negotiation environment. That is, the client is known to be a tough negotiator and has a stronger bargaining position relative to the auditor. Such a setting would be the most likely to benefit from a negotiation strategy that encourages a more collaborative negotiation environment. Thus, we expect the relative strength of the auditor's negotiating position and client management's negotiating style to interact to affect the auditor's use of a reciprocity-based strategy. Specifically,

\footnotetext{
${ }^{7}$ While the audit committee is responsible for engaging/terminating the auditor, discussions with several Big 4 partners (including a national officer in charge of practice issues) indicate that management's role in the auditor retention decision has not significantly diminished. Further, a recent survey of audit committee members and other executives finds that controllers/CFOs have the greatest influence (e.g., greater than the audit committee) over issues such as auditor compensation and retention (KPMG 2004).
} 
auditors will make greater use of a reciprocity-based strategy when confronted with a competitive

client and high client retention risk. We therefore test the following hypothesis:

H3: Client negotiating style and retention risk will interact to affect auditors' use of a reciprocity-based strategy such that greatest use of the strategy (beyond the predicted main effects) will occur for competitive clients with high retention risk.

\section{EXPERIMENT 1}

\section{Task and Procedure}

Participants were sixty audit managers and partners from large, international public accounting firms who had, on average, about 10 years experience. ${ }^{8}$ Prior research and discussions with practicing auditors revealed that managers and partners would be familiar with the process of negotiating with clients to resolve audit differences (e.g., Gibbins et al. 2001). Participants completed a computer-based instrument that simulated the process of resolving audit differences with client management. In the simulation participants were provided with detailed instructions for the task, a description and history of the client, current and prior year financial statements, and a list of items compiled by the audit senior in charge. This list of items included eight (incomedecreasing) audit differences to be reconciled with management/disposed of by the auditor. Of these eight items, four represented significant adjustments that audit experts determined should be posted to avoid material misstatement of the financial statements, while four items were clearly inconsequential to the financial statements. ${ }^{9}$ Items that are deemed inconsequential by the auditor are not required to be reported under the current regulatory environment. ${ }^{10}$

\footnotetext{
${ }^{8}$ There are no significant differences in mean years audit experience between the groups (overall mean $=10.05$ years; $\mathrm{p}$ $>.50$ ). Also, there are no significant differences (all p's > .20) between groups on other demographic variables (e.g., familiarity with relevant authoritative guidance, experience resolving audit differences). All participants completed this experiment after the adoption of SAS No. 89 and the Sarbanes-Oxley Act of 2002.

${ }^{9}$ Two of the significant items are judgmental in nature (relating to warranties and goodwill) and two are "hard" errors (relating to research and development costs and to sales). Of the four inconsequential items, two relate to judgmental items and two to hard errors. The nature of the judgmental inconsequential items would allow the auditor an opportunity to revisit the assumptions upon which the auditor's judgment was made, potentially altering the amount of any final
} 
The experiment took place in two phases (see Figure 1). The first phase involved determining which items to consider posting as audit adjustments. In preparation for discussing proposed adjustments with the client, participants prepared a preliminary list of items to bring to management. Specifically, for each of the eight items, participants indicated whether they would waive the item without bringing it to management's attention (i.e., management is never made aware of the item) or bring it to management as a proposed adjustment. For items they decide to bring to management, participants could choose to insist the item be posted or consider waiving it in view of client management.

\section{[Insert Figure 1]}

In the second phase of the experiment, participants determined which items must be posted by the client before issuing an unqualified opinion on the financial statements. After submitting the preliminary list of proposed adjustments to client management, participants interacted (through computer simulation) with management to discuss the items on the list. Participants considered whether or not they would waive any of the inconsequential items they brought to the client in an effort to get management to post the significant items. At this point, participants indicated which (if any) of the inconsequential items they would waive and which they would insist the client post. Participants then answered a series of case-related and demographic questions, including a check of the manipulations.

\footnotetext{
adjustment. However, combined, these adjustments (if made in full) represent $0.015 \%$ of net sales, with no effect on EPS. Additionally, the two inconsequential hard errors, combined, represent $0.014 \%$ of net sales, with no effect on EPS. ${ }^{10}$ The inconsequential proposed adjustments were determined to be "clearly inconsequential" by seven audit partners and managers. It was also determined by these experts that the inconsequential adjustments were small enough in magnitude that they would need neither to be brought to the attention of the audit committee nor included in the management representation letter to remain in compliance with SAS No. 89 or Sarbanes-Oxley. Accordingly, these inconsequential proposed adjustments could be waived by the auditor without ever having been brought to the attention of the client.
} 


\section{Independent Variables}

Two independent variables (client negotiating style and client retention risk) were manipulated between participants resulting in a 2x2 ANOVA design. Client negotiating style refers to the manager's predisposition to act as either a competitive or a collaborative negotiator. Prior research suggests that competitive negotiators act individualistically, avoid making concessions, and tend to prolong discussions in hopes of a "win-lose" outcome (e.g., Putnam 1990). Half of the participants (competitive client condition) were informed that discussions over proposed adjustments are often difficult and "contentious," that the manager has been extremely reluctant to post any audit adjustments, and that reaching agreement typically involves protracted discussions. The remaining half (collaborative client condition) were informed that the manager has been relatively reasonable during such discussions in the past and has a goal common to that of the auditor (i.e., fairly stated financial statements). These characteristics are consistent with collaborative negotiators discussed in prior literature (e.g., Putnam 1990). We operationalize client retention risk by manipulating whether or not the client is soliciting bids for next year's audit. Half of the participants were informed that the client is soliciting bids (high retention risk condition), while the other half received no such statement (low retention risk condition). ${ }^{11}$ Participants were randomly assigned to one of the four treatment groups.

\section{Dependent Variables}

Recall that, for a disclosure approach to be demonstrated, two separate actions must occur. First, auditors must choose to bring to client management inconsequential items that they are willing to waive. Second, they must waive these items in an effort to encourage management cooperation in the posting of significant adjustments. Therefore, we measure both: 1) the number of

\footnotetext{
11 This can be considered an indirect threat by the client. Prior research indicates that indirect threats are typically more effective than direct threats (Pruitt and Carnevale 1993).
} 
inconsequential adjustments included in the preliminary list of items to be viewed by management and 2) the number of inconsequential items waived (in view of management) by the participant during the negotiation process with the client. We also examine participants' initial decisions whether to waive or post the adjustments in order to determine their intent to use a reciprocity-based strategy. In deciding how to dispose of an audit difference participants could: 1) bring the item to the client with the intention that it should be posted; 2) bring the item to the client, but be willing to waive it if it helps get the client to agree to post other, more essential items; or 3) waive the item now without bringing it to the client's attention. Option 2 is indicative of a reciprocity-based strategy, in that items are brought to the client with the intention of waiving them to help persuade client management to make concessions.

\section{Experiment 1 Results}

Results are analyzed within a 2x2 ANOVA framework (client management's negotiating style condition by client retention risk condition). Due to the directional nature of expectations, all tests of hypotheses are one-tailed. Manipulation checks for both independent variables indicate that participants understood the manipulations. $^{12}$

\section{Client Management's Negotiating Style}

Hypothesis 1 predicts that participants in the competitive client condition will make greater use of a reciprocity-based strategy than will participants in the collaborative client condition. Consistent with this expectation, ANOVA results demonstrate that the competitive/collaborative manipulation significantly affects the number of inconsequential items brought to client

\footnotetext{
${ }^{12}$ On separate ten-point scales, participants were asked to respond to: a question relating to client management's general willingness to post audit adjustments $(1=$ "generally against posting adjustments" and $10=$ "generally open to posting adjustments") and a statement referring to the client's soliciting of bids for next year's audit ( 1 = "strongly disagree" and $10=$ "strongly agree"). Means were significantly different and directionally consistent with the manipulation for both questions (p's <.001). Mean responses to the first item were 1.77 and 8.83 for the competitive and collaborative client conditions, respectively, while mean responses to the second item were 8.77 and 2.03 for the high and low retention risk conditions, respectively.
} 
management on the preliminary list $(\mathrm{p}=.033$; Panel A of Table 1). Examination of the means (Table 1, Panel B) indicates that participants facing a competitive negotiator brought 2.47 inconsequential items to management, while participants facing a collaborative negotiator brought 1.77 inconsequential items, on average. Further, those in the competitive client condition were more likely to have brought these items to the client with the intention of waiving them to help persuade management to post the more significant items $(\mathrm{p}=.005$; Table 2, Panel A). Specifically, participants in the competitive client condition brought an average of 1.93 items they were willing to waive in order to help secure the posting of significant items compared to 1.07 such items for the collaborative client group (Table 2, Panel B). Participants in the competitive client condition also waived more inconsequential items (1.90 items) that they had earlier brought to management's attention (i.e., waived in view of management) than those in the collaborative client condition (1.07 items, $\mathrm{p}=.002$; Table 3 ). Taken together, these results are consistent with the expectation that auditors facing a competitively negotiating client will make greater use of a reciprocity-based negotiation strategy than those interacting with a collaborative client, providing support for H1.

[Insert Tables 1, 2, \& 3]

\section{Client Retention Risk}

Hypothesis 2 predicts that auditors in the high client retention risk condition will make greater use of a reciprocity-based negotiation strategy than will participants in the low retention risk condition. ANOVA results reported in Table 1 (Panel A) are consistent with this prediction. The retention risk manipulation significantly affects the number of inconsequential items brought to the attention of client management, with participants in the high risk condition bringing 2.47 items to management and those in the low risk condition bringing 1.77 , on average $(p=.033$; Table 1 , Panel B). Those in the high risk group were also more likely to have brought these items with the intention of waiving them, with the high (low) risk group bringing an average of 1.77 (1.23) items 
they were willing to waive in order to help secure the posting of significant items $(p=.051$; Table 2). Further, participants in the high risk condition actually waived more inconsequential items in view of client management (1.84 items) than those in the low risk condition $(1.14$ items, $\mathrm{p}=.007$; Table 3). These findings, when considered jointly, provide support for the $\mathrm{H} 2$ expectation that auditors will utilize a reciprocity-based strategy to a greater extent when there is a higher risk of losing the client.

\section{The Moderating Effect of Retention Risk on Client Management's Negotiation Strategy}

While results regarding the main effect hypotheses $(\mathrm{H} 1$ and $\mathrm{H} 2)$ are significant, they need to be viewed in the context of the interaction results $(\mathrm{H} 3)$. Hypothesis 3 predicts client retention risk will moderate the influence of client management's negotiating style on the extent to which auditors utilize a reciprocity-based strategy, such that auditors' use of a reciprocity-based strategy will be greatest when retention risk is high and the client is a competitive negotiator. With respect to the number of inconsequential items brought to client management's attention, ANOVA results indicate the interaction term is significant at $\mathrm{p}=.048$ (Table 1, Panel A). Further, the interaction term is also significant for the number of inconsequential items brought with the intention of waiving them to help persuade management to post the significant items $(\mathrm{p}=.021$; Table 2 , Panel $\mathrm{A})$, as well as the for the number of inconsequential items subsequently waived ( $\mathrm{p}=.007$; Table 3, Panel A). Figure 2 plots the means for the three dependent variables and demonstrates that client retention risk has the anticipated moderating effect on management's negotiating style, providing support for H3. It is important to note that the main effects found in the testing of $\mathrm{H} 1$ and $\mathrm{H} 2$ appear to be driven by the cell in which participants faced a competitive negotiator and the client was soliciting bids for next 
year's audit. ${ }^{13}$ Specifically, reciprocity is invoked only when the opponent is negotiating from a position of relative strength and is known to use contentious tactics, thus increasing the likelihood that this relative strength will be brought to bear.

\section{[Insert Figure 2]}

\section{Total Items Posted}

Interestingly, the end result of the negotiation process is similar regardless of client characteristics. Examining the total number of the original eight items that ultimately gets posted, non-tabulated results indicate that auditors in all conditions typically posted about four and a half items, on average, with no significant differences between conditions (p's > .50, two-tailed). ${ }^{14}$ This result suggests that greater use of a reciprocity-based strategy may have helped mitigate perceived client pressure (when present) to waive adjustments. Given that the purpose of experiment 1 is to explore whether and under what circumstances auditors will use a reciprocity-based strategy (and not to consider the ultimate effect on the financial statements), its context and client management responses are not designed to allow us to examine auditor actions when management resists posting significant items. As auditors perceive this type of reciprocity-based strategy to be useful for improving client relations in an environment where significant items must be posted (Sanchez et al. 2007), it may be that using this strategy helps the auditor cope with perceived management pressures to waive or reduce significant proposed adjustments, potentially leading to higher quality financial statements. In experiment 2, we more directly explore the influence of a reciprocity-based strategy on the financial statements in such a negotiation setting.

\footnotetext{
${ }^{13}$ Post-hoc tests (Duncan's multiple means comparison where alpha $\left.=.05\right)$ indicate that only the means in Cell $4($ where client management is competitive and retention risk is high) are different from the other means for all dependent variables.

${ }^{14}$ The average number of inconsequential items posted was .63 items. This number was not significantly different across conditions (p's $>.50$ ). Further examination of the data reveals that only one participant posted just three of the four significant items, resulting in no significant differences between conditions with respect to the posting of significant items (p's > .40).
} 


\section{EXPERIMENT 2}

\section{The Effect of Strategy Use on Auditors' Negotiation Demands}

Experiment 2 is designed to address the question of whether a reciprocity-based strategy helps the auditor negotiate more conservative adjustments to the financial statements (through reducing perceived client pressure) when dealing with a contentious negotiation setting. Recall that a primary reason experienced negotiators use reciprocity is to induce concessions from their opponents. That is, it is easier to ask concessions of others when one offers a concession in return (Cialdini 2001). Further, Cialdini (2001) suggests that a small favor (e.g., concession) can create an obligation to agree to a significantly larger one. Thus, through an appropriate use of reciprocity, an auditor may believe he or she can influence the extent to which a contentious client manager will resist/contend. That is, auditors may anticipate less client resistance and, in turn, be more ambitious negotiators when employing reciprocity while resolving audit differences.

Negotiation parameters such as negotiation goals (i.e., the adjustment amount the auditor hopes to achieve through negotiation) and limits (i.e., the minimum adjustment the auditor would allow before qualifying the opinion) have proven to correlate highly with negotiation success (e.g., Ben-Yoav and Pruitt 1984; Kelly et al. 1967). Therefore, we examine auditors' negotiation goals and limits (as well as their counter-offers) to consider how the use of a reciprocity-based strategy affects auditors' likely success in the negotiation process. Specifically, we expect that, in a contentious negotiation setting, the use of a reciprocity-based strategy will improve the auditor's negotiation parameters and demands (i.e., negotiation goals, limits, and counter-offers) and that this effect will be due to a perceived reduction in client pressure to waive/reduce adjustments (see Figure 3). This leads to the following hypotheses:

H4: In contentious negotiation settings, auditors who employ a reciprocity-based strategy will have more ambitious negotiation parameters and demands (leading to more conservative financial statements) than auditors who do not employ such a strategy. 
H5: Perceived client pressure to waive or reduce a proposed adjustment will mediate the relationship between auditors' use of a reciprocity-based strategy and their negotiation parameters and demands.

\section{[Insert Figure 3]}

\section{Task and Procedure}

Participants were 40 audit managers and partners from large, international public accounting firms who had, on average, about 9.7 years experience. ${ }^{15}$ Similar to experiment 1 , participants completed a computer-based instrument that simulated the process of resolving audit differences with client management. They were provided with task instructions, a description of the client, current and prior year financial statements, and the "preliminary audit team findings" compiled by the audit senior and shared with the client manager (prior to negotiation). The preliminary findings include a significant, and subjective (or "soft"), adjustment of $\$ 2,540,000$ relating to an estimate of warranty expense. We chose a subjective adjustment because such items are frequently negotiated and are often more contentious and more difficult to convince the client to record (e.g., Wright and Wright 1997; Beattie et al. 2000; Gibbins et al. 2001). ${ }^{16}$ Depending on treatment condition (discussed below), the preliminary findings also included either three or no clearly inconsequential items. The three inconsequential items and amounts are based on those used in experiment 1 (two soft "judgmental" items and one hard item).

All participants were informed that discussions with the client manager over proposed adjustments are often "difficult and protracted" and that the client is soliciting bids for next year's audit (similar to cell 4 from experiment 1). After considering the preliminary audit findings, participants answered questions relating to their preparation and expectations for their meeting to

\footnotetext{
${ }^{15}$ There are no significant differences between groups (p's > .50) for years of audit experience or any other demographic variable (e.g., familiarity with relevant authoritative guidance, experience resolving audit differences).

${ }^{16}$ Further, a significant adjustment based on an estimate allows for a richer negotiation context than an objective one, in that the auditor and client management can negotiate over the amount of the adjustment to be booked (and not only over whether the item should be booked).
} 
discuss the significant item with the client, which was followed by the interaction itself. Participants then responded to a series of case-related and demographic questions, including a manipulation check.

\section{Dependent Variables}

We examine auditors' negotiation goals, limits, and counter-offers to gain insight into how auditors' use of a reciprocity-based strategy may influence the magnitude of the negotiated adjustments to the financial statements. The negotiation goal represents the adjustment amount the auditor strives to have the client post at the end of negotiations with management. The minimum required adjustment (or "negotiation limit") represents the lowest adjustment (i.e., least conservative) amount the auditor would be willing to accept without requiring that the audit opinion be qualified. Prior research demonstrates that more ambitious goals and negotiation limits lead to better outcomes for the negotiator (e.g., Ben-Yoav and Pruitt 1984; Kelly et al. 1967) and thus, since actual auditor-client manager negotiation is logistically impractical in an experimental setting, we focus on these two measures.

In addition, we had participants engage in two rounds of (programmed) negotiation in which they respond to counter-offers by the client manager. In the first round, the manager counters the initial proposed warranty adjustment (i.e., the figure of $\$ 2,540,000$ included in the preliminary audit findings) with an offer to post a $\$ 500,000$ adjustment. Participants then decided whether to accept the manager's offer or make a counter-offer (which participants could choose as the full amount of the initial proposed adjustment). If the auditor did not accept the manager's offer, the manager made a second counter-offer which "splits the difference" (i.e., half way) between the two positions. Again, the auditors could choose to accept the manager's revised offer or make a second counteroffer. At this point, the client agrees to post an adjustment equal to the amount of the auditor's second counter-offer. 


\section{Independent and Mediating Variables}

For experiment 2, we manipulate a single independent variable (whether or not a reciprocity-based strategy is employed by the auditor) between participants. In the "reciprocity strategy" condition, the preliminary audit findings included three clearly inconsequential items. The engagement partner suggested that, given the inconsequential nature of these three items, the auditor might consider starting the meeting with the client manager by waiving them and then focusing on the significant item. In the "no reciprocity strategy" condition, the preliminary audit findings included only the significant item (i.e., no inconsequential items), which the engagement partner reminded the auditor will be the focus of their meeting with the client. We also measured how much resistance participants expect from the client during negotiations over the significant item (i.e., perceived pressure to waive/reduce the adjustment).

\section{Experiment 2 Results}

\section{Negotiation Goals, Limits, and Counter-Offers}

Hypothesis 4 predicts that participants in the reciprocity strategy condition will have greater (more ambitious) negotiation parameters/demands than those that do not have the strategy available to them. Results presented in Table 4 are consistent with this expectation. ${ }^{17}$ Auditors' negotiation goals (i.e., the adjustment amount they strive for during negotiation) are significantly higher with strategy use than without it (means $=\$ 2,394,091$ and $\$ 1,924,091$, respectively; $p=.002)$. Similarly, auditors' negotiation limits (i.e., minimum acceptable adjustment amount) are significantly greater when the strategy is used than when it not available (means $=\$ 1,957,727$ and $\$ 1,315,909$, respectively; $\mathrm{p}=.003)$. First and second counter-offers are also significantly higher with strategy

\footnotetext{
${ }^{17}$ We perform t-tests to determine differences between our two conditions. All tests of directional expectations are onetailed.
} 
use than without it (first counter means $=\$ 2,201,818$ and $\$ 1,758,636$, respectively, $\mathrm{p}=.001$; second counter means $=\$ 1,969,091$ and $\$ 1,417,500$, respectively, $\mathrm{p}=.001) .^{18}$

[Insert Table 4]

\section{Mediating Influence of Perceived Pressure to Concede to Client}

The results of experiment 1 , indicating that auditors make greater use of a reciprocity-based strategy when facing a difficult negotiation, suggest that auditors may use such a strategy in an effort to reduce perceived pressure from the client to concede. Experiment 2 allows us to examine whether the use of a reciprocity-based strategy reduces the pressure auditors feel heading into a negotiation and, in turn, whether this reduction in pressure helps explain why auditors demand larger adjustments with strategy use. Specifically, we predict that perceived client pressure mediates the relationship between strategy use and negotiation demands.

According to Baron and Kenny (1986), the mediation effect we predict would be indicated if the following three conditions are met. First, the independent variable Strategy Use (STRAT) must affect the presumed mediator Perceived Client Pressure (PRESS) (path A in Figure 3). Second, the independent variable must affect the dependent variables Negotiation Goal (GOAL) and Minimum Required Adjustment (MIN) (path C in Figure 3). Third, the mediator must affect the dependent variables in the presence of the independent variable (path B in Figure 3). If this final condition holds, then the effect of the independent variable on the dependent variable will be reduced or eliminated in the presence of the mediator.

Table 5 reports results for these regressions. To test for the mediation effect predicted by H5, we focus on whether the three conditions discussed above have been satisfied. ${ }^{19}$ The results

\footnotetext{
18 Although the inconsequential items would be waived in any event, we also consider the net "visible concession" by adding the dollar amount of the inconsequential items to the amount conceded on the significant item by reciprocity strategy condition participants. Including these items as part of the reciprocity strategy group's visible concession, the strategy group still concedes significantly less than the no strategy group (all p's $<.055$ for goal, limit, and both counter-offers).

${ }^{19}$ For the mediation analysis, all reported $p$-values are two-tailed.
} 
reveal that condition one is satisfied, as the coefficient on STRAT is positive and significant $(\mathrm{p}<$ .001). Similarly, the coefficient on STRAT is positive and significant $(\mathrm{p}=.003$ for GOAL and $\mathrm{p}=$ .005 for MIN), satisfying condition two. The coefficient on PRESS is, as expected, negative and significant $(\mathrm{p}=.033$ for GOAL and $\mathrm{p}=.006$ for MIN), satisfying condition three. We further find that the mediation effects are significant $(Z=1.89, p=.030$ for GOAL and $Z=2.13, p=.017$ for MIN). ${ }^{20}$ Thus, our results demonstrate that perceived client pressure mediates the effect of strategy use on auditors' negotiation demands. Finally, notice that the coefficients on the manipulated variable (STRAT) become both smaller and insignificant when the mediator (PRESS) is included in the regressions, which demonstrates full mediation for both dependent variables (GOAL and MIN).

\section{DISCUSSIONS AND CONCLUDING REMARKS}

The current regulatory environment (e.g., the Sarbanes-Oxley Act of 2002), brought on by recent high-profile audit failures, has placed auditors of financial statements under increased scrutiny. While the financial statements of an organization are considered the responsibility of management, negotiations between auditors and their clients regarding the contents of the financial statements are quite common and may affect accounting disclosure (Antle and Nalebuff 1991; Gibbins et al. 2001). Prior research has suggested that a company's financial statements can be affected by the negotiation strategy employed by the auditor when resolving audit differences with the client (Antle and Nalebuff 1991). Research has also found that altering the auditor's strategy/approach to the negotiation process can have positive effects on the negotiated outcome, as well as the relationship between the auditor and client (Trotman et al. 2005; Sanchez et al. 2006). Our study extends the literature by investigating, in a post-Sarbanes-Oxley environment, whether auditors will employ a reciprocity-based strategy for the resolution of audit differences and what

\footnotetext{
${ }^{20}$ The $\mathrm{Z}$ statistic is based on a numerator which is the product of the indicated coefficients from Equations (1) and (3) (from Table 5) and the denominator is the estimation of the standard deviation $(\sigma)$ for the mediating effect (MacKinnon and Dwyer 1993). Also, we find similar regression and mediation results for the first and second counter-offers.
} 
client characteristics will increase the extent to which it is utilized. Such a strategy involves both bringing inconsequential items to client management and subsequently waiving these items in an effort to encourage management to be more cooperative in the posting of significant adjustments. Further, we explore the potential effects of a reciprocity-based strategy on the quality of the financial statements.

Results of experiment 1 indicate that client management's negotiating strategy and retention risk have an interactive effect on auditors' use of a reciprocity-based strategy (i.e., bringing inconsequential items to client management and subsequently waiving them). Consistent with our expectations, auditors made greater use of a reciprocity-based strategy when confronted with a competitive negotiator and greater client retention risk. Experiment 2 findings suggest that auditors are more effective negotiators demanding larger adjustments by the client, when the strategy is employed than when no such strategy is available. Further, this relationship is mediated by the strategy's effect on auditors' perceived pressure from the client to reduce/waive adjustments. Our results, in conjunction with prior findings (Sanchez et al. 2007), suggest that auditors may utilize a reciprocity-based strategy in difficult negotiation conditions where the strategy could potentially improve audit quality by both reducing pressure to accept the client's position and reducing client resistance to the auditor's position. These findings are particularly relevant given recent research demonstrating that pressure from the client increases the likelihood that auditors will waive/reduce proposed audit adjustments (Hatfield et al. 2006).

The findings of this study have implications for practice and future research. With respect to practice, results of this study suggest that auditors alter their negotiation strategies dependent upon the characteristics of the client. Our results show that, under certain client characteristics, auditors will engage in a negotiating approach designed to produce a more collaborative negotiation environment. The observation that auditors have been found to waive adjustments or alter estimates 
during the negotiation process (e.g., Gibbins et al. 2001; Braun 2001) could be part of a negotiation strategy and does not necessarily indicate that auditors are signing off on financial statements that differ from the auditors' initial intended outcome. Future research could investigate and compare auditors' intended outcomes with the actual outcome of the negotiation. While this and other studies (e.g., Sanchez et al. 2007) suggest that reciprocity-based strategies enhance both the current negotiation and the relationship of negotiators, further research could examine the use of reciprocity-based strategies (and other negotiation strategies) in multi-period, multi-negotiation contexts. Finally, while the negotiation itself can be conducted in a variety of ways (e.g., face-toface interaction, by telephone, electronically, through third parties), our study utilizes only a computer-based (simulated) interaction with the client management. Future research could investigate other methods of interaction between negotiating parties. Such research will further our understanding of auditor negotiation strategy use and its effect on the financial statements, as well as on the relationship between auditors and their clients. 
FIGURE 1

Outline of Experiment 1 Procedure

\section{Phase 1: Assemble Preliminary List of Audit Differences}

Participants:

- asked to assume role of auditor on hypothetical engagement and become familiarized with hypothetical company

- asked to assume they will communicate with client management regarding proposed financial statement adjustments

- receive client characteristics manipulations:

client management's negotiating style (collaborative versus competitive)

client retention risk (low versus high)

- view a list of eight audit differences discovered by the staff auditor and determine which items to bring to management on a preliminary list

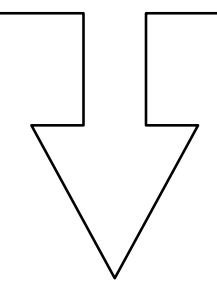

\section{Phase 2: Resolution of Audit Differences}

Computer-simulated interaction with client management reveals that management agrees to post the significant items, but requests participant to waive the inconsequential items brought to negotiation

Participants:

- indicate which (if any) of the inconsequential items they will waive and which must be posted

- respond to demographic and manipulation check prompts 
FIGURE 2

The Interactive Effect of Client Management's Negotiating Strategy and Retention Risk

Panel A: Dependent Variable $=$ Number of Inconsequential Items Brought to Client

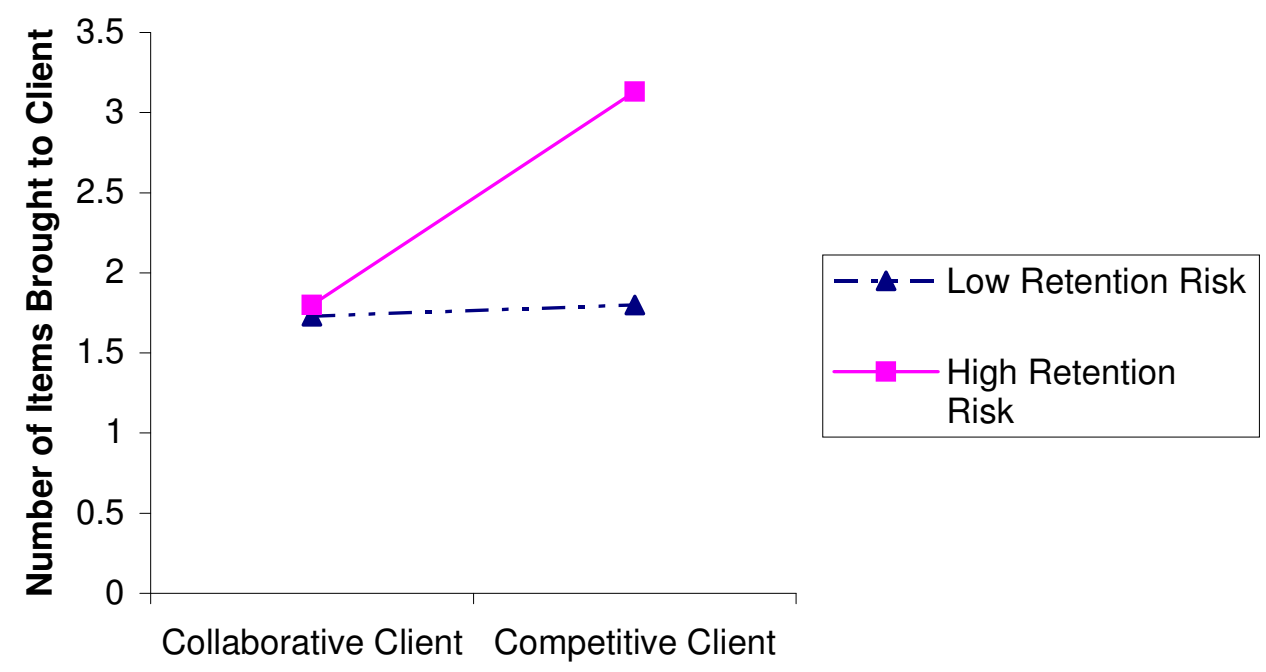

Panel B: Dependent Variable $=$ Number of Inconsequential Items Brought with Intent to Waive

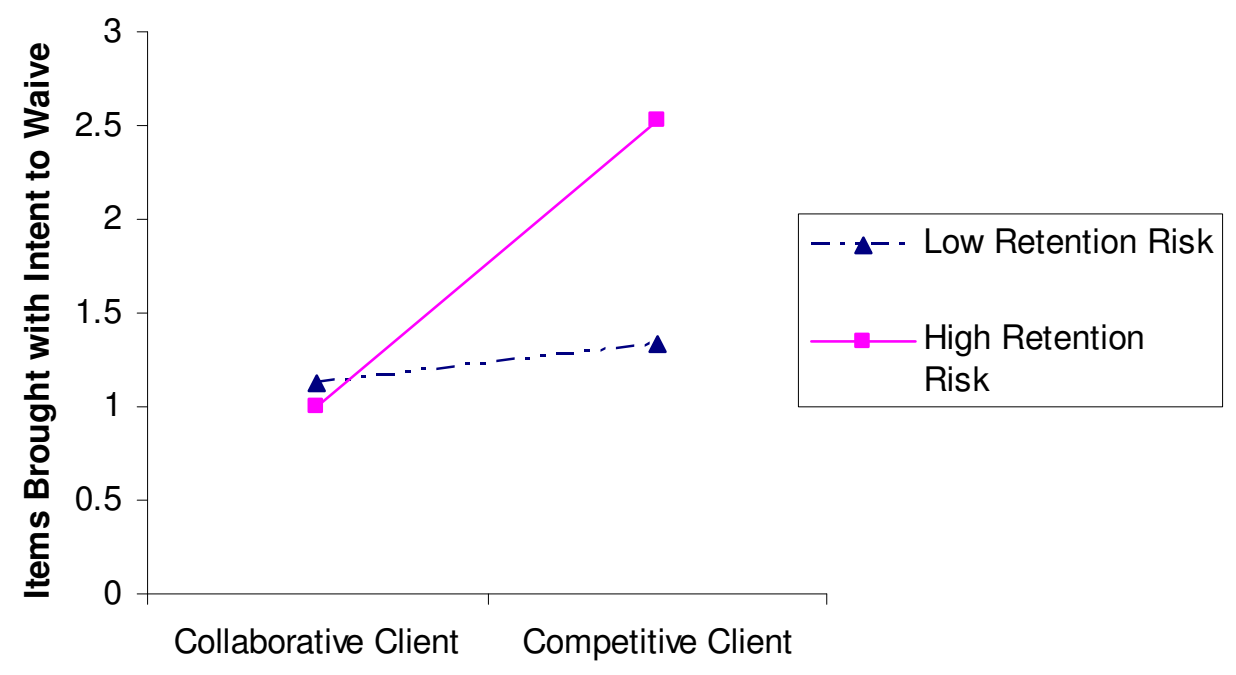


Panel C: Dependent Variable $=$ Number of Inconsequential Items Waived

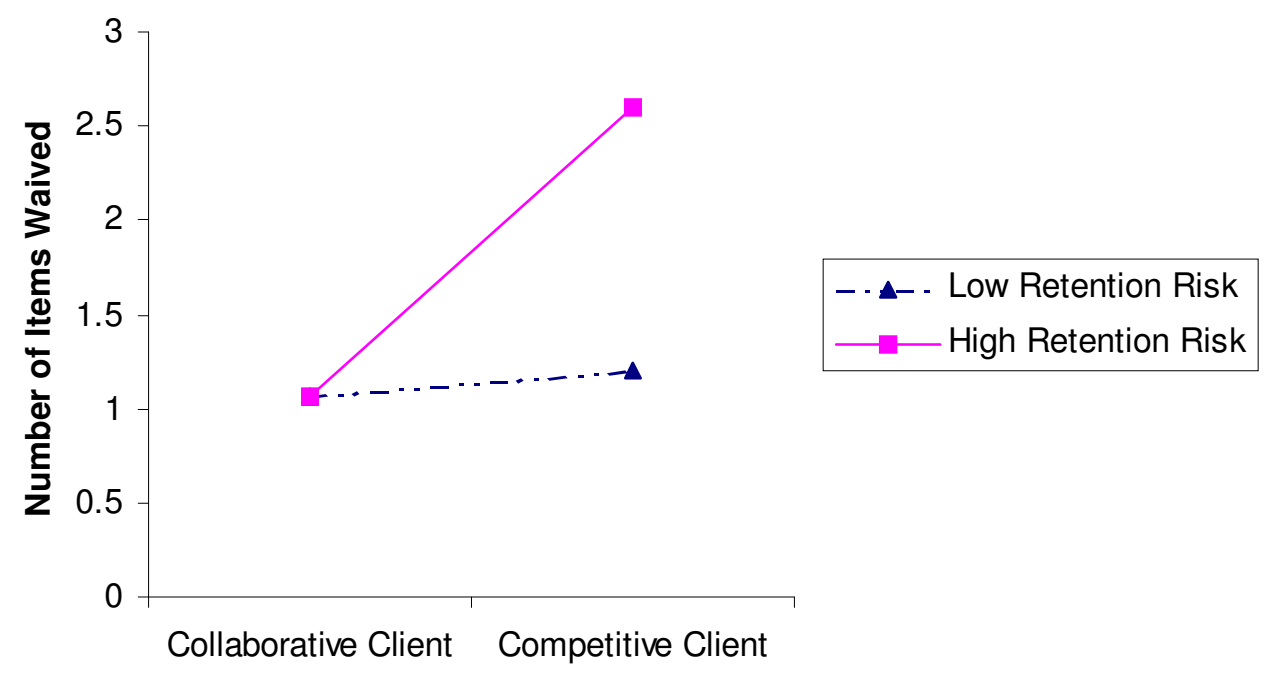


FIGURE 3

Mediation Model

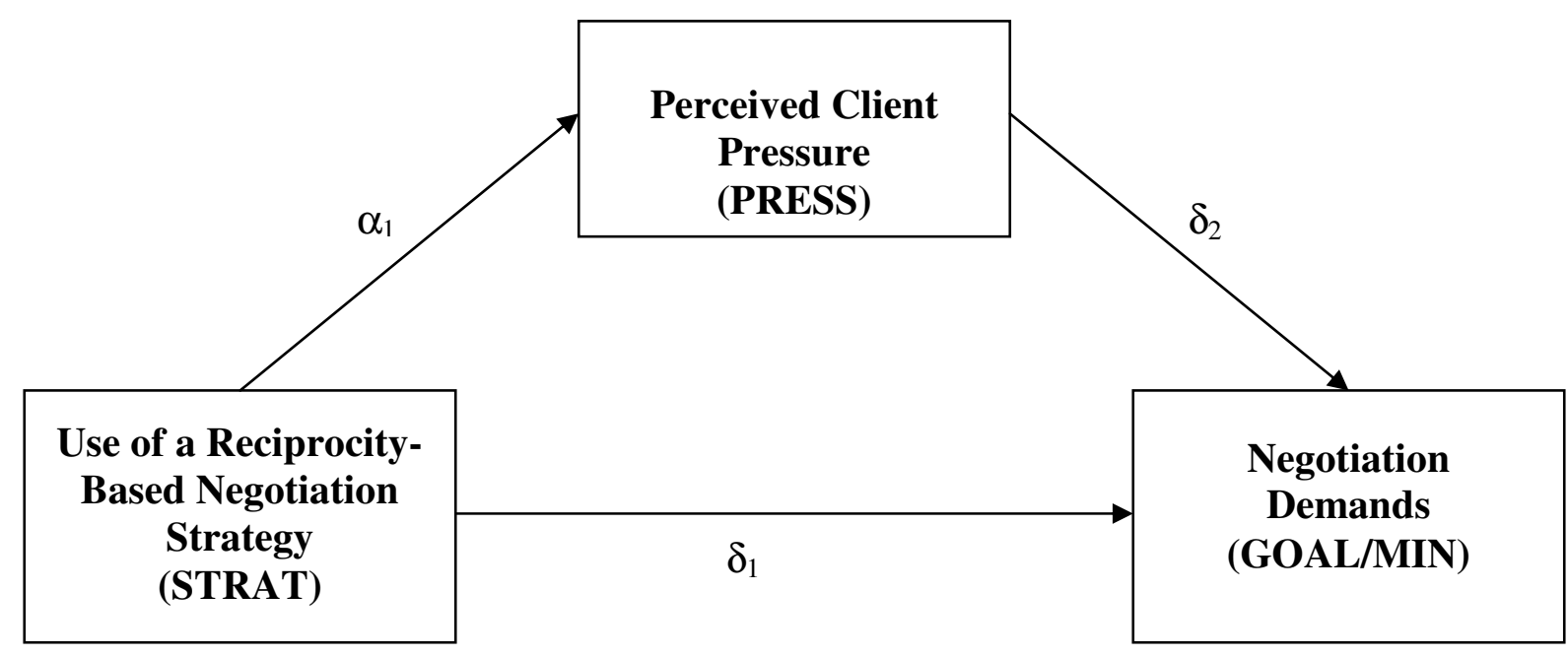

The regressions from which these coefficients are obtained are specified as follows:

$$
\begin{aligned}
& \text { PRESS }_{\mathrm{i}}=\alpha_{0}+\alpha_{1} \text { STRAT }_{\mathrm{i}}+\varepsilon_{\mathrm{i}} \\
& \text { GOAL } \mathrm{MIN}_{\mathrm{i}}=\gamma_{0}+\gamma_{1} \mathrm{STRAT}_{\mathrm{i}}+\varepsilon_{\mathrm{i}} \\
& \text { GOAL } / \mathrm{MIN}_{\mathrm{i}}=\delta_{0}+\mathrm{STRAT}_{\mathrm{i}}+\delta_{2} \text { PRESS }_{\mathrm{i}}+\varepsilon_{\mathrm{i}}
\end{aligned}
$$

To determine the significance of the mediating effects, $\mathrm{Z}$ statistics are calculated (MacKinnon and Dwyer 1993) with the coefficients and standard deviations $(\sigma)$ from equations (1) and (3) using the following formula:

$$
\mathrm{Z}=\frac{\alpha_{1} \delta_{2}}{\sqrt{\alpha_{1}^{2} \sigma_{\delta}^{2}+\delta_{2}^{2} \sigma_{\alpha}^{2}-\sigma_{\alpha}^{2} \sigma_{\delta}^{2}}}
$$


TABLE 1

Experiment 1: Number of Inconsequential Items Brought to Client Management $(n=60)$

Panel A: ANOVA Results for Number of Inconsequential Items Brought to Client

\begin{tabular}{llcc} 
Independent Variable & df & F-Statistic & p-value $^{\text {a }}$ \\
\hline Competitive/Collaborative Client & 1 & 3.504 & .033 \\
Retention Risk & 1 & 3.504 & .033 \\
Interaction & 1 & 2.868 & .048
\end{tabular}

Panel B: Mean (Standard Deviation) Number of Inconsequential Items Brought to Client

Low Retention Risk

High Retention Risk

Column Means

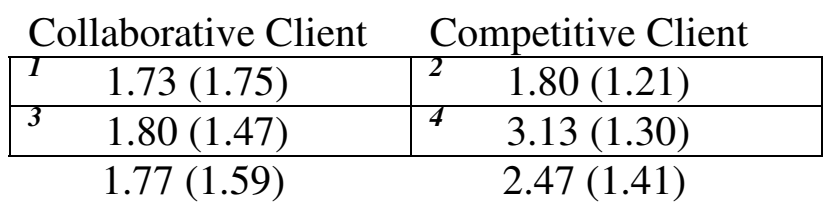

Row Means

$1.77(1.48)$

$2.47(1.53)$

${ }^{\mathrm{a}} \mathrm{p}$-values are based on one-tailed tests since expectations were directional.

${ }^{\mathrm{b}}$ For all cells (1-4), $\mathrm{n}=15$. 
TABLE 2

Experiment 1: Inconsequential Items Brought to Client with Intent to Waive $(n=60)$

Panel A: ANOVA Results for Inconsequential Items Brought to Client with Intent to Waive

\begin{tabular}{llcc} 
Independent Variable & df & F-Statistic & p-value $^{\text {a }}$ \\
\hline Competitive/Collaborative Client & 1 & 7.269 & .005 \\
Retention Risk & 1 & 2.753 & .051 \\
Interaction & 1 & 4.301 & .021
\end{tabular}

Panel B: Mean (Standard Deviation) Inconsequential Items Waived ${ }^{\text {b }}$

Low Retention Risk

High Retention Risk

Column Means

\begin{tabular}{|c|c|}
\hline Collaborative Client & Competitive Client \\
\hline $\begin{array}{ll}T & 1.13(1.55)\end{array}$ & $2 \quad 1.33(0.72)$ \\
\hline $1.00(1.07)$ & $2.53(1.46)$ \\
\hline $1.07(1.311)$ & $1.93(1.285)$ \\
\hline
\end{tabular}

Row Means

$1.23(1.194)$

$1.77(1.478)$

${ }^{a}$ All reported p-values are based on one-tailed tests since expectations were directional.

${ }^{\mathrm{b}}$ For all cells (1-4), $\mathrm{n}=15$. 
TABLE 3

Experiment 1: Number of Inconsequential Items Waived $(n=60)$

Panel A: ANOVA Results Number of Inconsequential Items Waived

Independent Variable

Competitive/Collaborative Client

$\begin{array}{ccc}\text { df } & \text { F-Statistic } & \text { p-value }^{\mathrm{a}} \\ 1 & 9.134 & .002 \\ 1 & 6.445 & .007 \\ 1 & 6.445 & .007\end{array}$

Panel B: Mean (Standard Deviation) Number of Inconsequential Items Waived ${ }^{\mathrm{b}}$

Low Retention Risk

High Retention Risk Column Means

\begin{tabular}{|c|c|}
\hline Collaborative Client & Competitive Client \\
\hline $\begin{array}{ll}T & 1.07(1.22) \\
\end{array}$ & $\begin{array}{l}2 \\
\end{array}$ \\
\hline $1.07(1.03)$ & $2.60(1.24)$ \\
\hline $1.07(1.11)$ & $1.90(1.21)$ \\
\hline
\end{tabular}

Row Means

$1.14(0.97)$

$1.84(1.37)$

${ }^{a}$ All reported p-values are based on one-tailed tests since expectations were directional.

${ }^{\mathrm{b}}$ For all cells (1-4), $\mathrm{n}=15$. 
TABLE 4

Experiment 2: Effect of Reciprocity Strategy on Auditors' Negotiation Demands

\begin{tabular}{|c|c|c|c|c|}
\hline Dependent Variable $^{\mathrm{a}}$ & $\begin{array}{l}\text { Reciprocity } \\
\text { Strategy } \\
(\mathrm{n}=22) \\
\end{array}$ & $\begin{array}{c}\text { No Reciprocity } \\
\text { Strategy } \\
(\mathrm{n}=22) \\
\end{array}$ & t-Statistic & p-value ${ }^{b}$ \\
\hline $\begin{array}{l}\text { Negotiation Goal } \\
\text { Mean } \\
\text { (Std. Dev.) }\end{array}$ & $\begin{array}{r}\$ 2,394,091 \\
(278,818)\end{array}$ & $\begin{array}{r}\$ 1,924,091 \\
(629,101)\end{array}$ & 3.20 & .002 \\
\hline $\begin{array}{c}\text { Minimum Required } \\
\text { Adjustment (Limit) } \\
\text { Mean } \\
\text { (Std. Dev.) }\end{array}$ & $\begin{array}{r}\$ 1,957,727 \\
(643,694)\end{array}$ & $\begin{array}{r}\$ 1,315,909 \\
(777,975)\end{array}$ & 2.98 & .003 \\
\hline $\begin{array}{c}\text { First Counter-Offer } \\
\text { Mean } \\
\text { (Std. Dev.) }\end{array}$ & $\begin{array}{c}\$ 2,201,818 \\
(366,484)\end{array}$ & $\begin{array}{r}\$ 1,758,636 \\
(337,530)\end{array}$ & 4.17 & .001 \\
\hline $\begin{array}{c}\text { Second Counter-Offer } \\
\text { Mean }^{\text {c }} \\
\text { (Std. Dev.) }\end{array}$ & $\begin{array}{r}\$ 1,969,091 \\
(494,271)\end{array}$ & $\begin{array}{r}\$ 1,417,500 \\
(452,658)\end{array}$ & 3.86 & .001 \\
\hline
\end{tabular}

${ }^{a}$ Negotiation Goal represents the negotiated outcome for which the participant is striving. Minimum Required Adjustment represents the lowest adjustment amount the participant would accept without qualifying the audit opinion. First Counter-Offer is the participant's response to the client's initial counter-offer of $\$ 500,000$. Second Counter-Offer is the participant's response to the client's second counter-offer which equals: $\$ 500,000+$ (auditor's first counter-offer $-\$ 500,000) / 2$, representing a "split-the-difference" strategy by the client.

${ }^{\mathrm{b}}$ All reported $\mathrm{p}$-values are based on one-tailed tests since expectations were directional. 


\section{TABLE 5}

\section{Regression Analyses for Perceived Client Pressure as a Mediating Influence}

\section{Coefficients}

\begin{tabular}{|c|c|c|c|}
\hline \multirow[b]{2}{*}{ Dependent Variable } & \\
\hline & Intercept & $\begin{array}{c}\text { Strategy Use } \\
\left(_{\text {STRAT })^{b}}\right.\end{array}$ & PRESS $^{b}$ \\
\hline 1) Perceived Client Pressure (PRESS) & 8.46 & -3.00 & \\
\hline Standard error & .407 & .575 & \\
\hline p-value (two-tailed) & $<.001$ & $<.001$ & \\
\hline \multicolumn{4}{|l|}{ 2) Negotiation Demands: } \\
\hline a) Negotiation Goal (GOAL) & $\$ 1,924,091$ & $\$ 470,000$ & \\
\hline Standard error & $\$ 103,738$ & $\$ 146,707$ & \\
\hline p-value (two-tailed) & $<.001$ & .003 & \\
\hline b) Minimum Required Adjustment (MIN) & $\$ 1,315,909$ & $\$ 641,818$ & \\
\hline Standard error & $\$ 152,225$ & $\$ 215,279$ & \\
\hline p-value (two-tailed) & $<.001$ & .005 & \\
\hline \multicolumn{4}{|l|}{ 3) Negotiation Demands: } \\
\hline a) Negotiation Goal (GOAL) & $\$ 2,626,391$ & $\$ 220,797$ & $-\$ 83,068$ \\
\hline Standard error & $\$ 333,463$ & $\$ 180,191$ & $\$ 37,354$ \\
\hline p-value (two-tailed) & $<.001$ & .227 & .033 \\
\hline b) Minimum Required Adjustment (MIN) & $\$ 2,612,842$ & $\$ 181,616$ & $-\$ 153,401$ \\
\hline Standard error & $\$ 472,065$ & $\$ 255,086$ & $\$ 53,304$ \\
\hline p-value (two-tailed) & $<.001$ & .481 & .006 \\
\hline
\end{tabular}

${ }^{a}$ Note: The regressions are specified as follows:

$$
\begin{aligned}
& \text { PRESS }_{i}=\alpha_{0}+\alpha_{1} \text { STRAT }_{i}+\varepsilon_{\mathrm{i}} \\
& \text { GOAL/MIN }_{\mathrm{i}}=\gamma_{0}+\gamma_{1} \text { STRAT }_{\mathrm{i}}+\varepsilon_{\mathrm{i}} \\
& \text { GOAL/MIN }_{\mathrm{i}}=\delta_{0}+\delta_{1} \text { STRAT }_{\mathrm{i}}+\delta_{2} \text { PRESS }_{\mathrm{i}}+\varepsilon_{\mathrm{i}}
\end{aligned}
$$

where: Strategy Use (STRAT) was coded as 0 when the strategy was not available and 1 when strategy was used; Perceived Client Pressure (PRESS) is a scaled variable from 1 (little perceived pressure) to 10 (much perceived pressure); and Negotiation Demands are represented by two measures Negotiation Goal (GOAL) which represents the negotiated outcome the participant is striving for, and Minimum Required Adjustment (MIN) which represents the smallest adjustment the participant would accept without qualifying the audit opinion. Since there are two dependent variables, two groups of regressions were run to examine the mediating effect of PRESS on both GOAL and MIN. ${ }^{b}$ Since strategy use and perceived pressure have directionally predicted effects, one-tailed p-values are reported. 


\section{REFERENCES}

American Institute of Certified Public Accountants (AICPA). 1999. Audit Adjustments. Statement on Auditing Standards No. 89. New York, NY: AICPA.

Antle, R., and B. Nalebuff. 1991. Conservatism and auditor-client negotiations. Journal of Accounting Research 29(Supplement):31-54.

Arel, B., R. G. Brody, and K. Pany. 2005. Audit firm rotation and audit quality. The CPA Journal 75 (1):36-39.

Benton, A. A., H. H. Kelley, and B. Liebling. 1972. Effects of extremity of offers and concession rate on the outcomes of bargaining. Journal of Personality \& Social Psychology 25: 219226.

Bame-Aldred, C. W., and T. Kida. 2007. A Comparison of Auditor and Client Negotiation Decisions. Accounting Organizations and Society, (forthcoming).

Braun, K. 2001. The disposition of audit-detected misstatements: An examination of risk and reward factors and aggregation effects. Contemporary Accounting Research 18 (1): 71-99.

Brown, H.L. and K. Johnstone. 2005. Effects of engagement risk and auditor negotiation experience on the process and outcomes of client-auditor negotiations. Working Paper, Boston College.

Cialdini, R. B. 2001. Influence. Third Edition. New York, NY: HarperCollins College Publishers.

Cialdini, R. B., and K. Ascani. 1976. Test of a concession procedure for inducing verbal, behavioral, and further compliance with a request to give blood. Journal of Applied Psychology 61: 295-300.

Gibbins, M., S. Salterio and A. Webb. 2001. Evidence about auditor-client management negotiation concerning client's financial reporting. Journal of Accounting Research 39 (3): 535-563.

Gouldner, A.W. 1960. The norm of reciprocity: A preliminary statement. American Sociological Review, 25: 161-178.

Hatfield, R.C., S.B. Jackson, and S.D. Vandevelde. 2006. The effects of auditor rotation and client pressure on proposed audit adjustments. Working Paper, The University of Alabama.

Hornstein, H.A. 1965. Effects of different magnitudes of threat upon interpersonal bargaining. Journal of Experimental Social Psychology, 1: 282-293.

Joe, J., A. Wright, and S. Wright. 2005. The Impact of Changes in the Reporting Environment, Client Characteristics, and Misstatement Type on the Disposition of Proposed Audit Adjustments. Working Paper, Georgia State University.

Johnson, D.W., R. Johnson, and G. Maruyama. 1984. Goal interdependence and interpersonal attraction in heterogenous classrooms: A metanalysis. Groups in contact: The psychology of desegregation, 187-212. New York: Academic Press. 
Kelley, H.H. 1997. Expanding the analysis of social orientations by reference to the sequentialtemporal structure of situations. European Journal of Social Psychology, 27: 373-404.

KPMG 2004. Oversight of auditors: Audit committee roundtable highlights. Audit Committee Insights (Spring).

Lax, D.A. and J.K. Sebenius. 1986. The manager as negotiator. New York: Free Press.

Michener, H. A., J. J. Vaske, S. L. Schleiffer, J. G. Plazewski, and L. J. Chapman 1975. Factors affecting concession rate and threat usage in bilateral conflict. Sociometry, 38:62-80.

Miller, R. L., C. Seligman, N. T. Clark, and M. Bush. 1976. Perceptual contrast versus reciprocal concession as mediators of induced compliance. Canadian Journal of Behavioral Science, 8: 401-409.

Nelson, M. W., J. A. Elliott, and R. L. Tarpley. 2002. Evidence from auditors about managers' and auditors' earnings-management decisions. The Accounting Review (Supplement):175-202.

$\mathrm{Ng}$, T. and H. Tan. 2003. Effects of authoritative guidance availability and audit committee effectiveness o auditors' judgments in an auditor-client negotiation context. The Accounting Review 78 (July): 801-818

Olekalns, M. and P.L. Smith. 2000. Understanding Optimal Outcomes. Human Communication Research 26,4: 527-557.

Pruitt, D., and P. Carnevale. 1993. Negotiation in Social Conflict. Pacific Grove, CA: Books/Cole Publishing.

Public Company Accounting Oversight Board. 2004. An audit of internal control over financial reporting performed in conjunction with an audit of financial statements. Audit Standard No. 2, PCAOB Release No. 2004-001 March 9, 2004.

Putnam, L. L. 1990. Reframing integrative and distributive bargaining: A process perspective. Research on Negotiation in Organizations 2: 3-30.

Sanchez, M. H., C. P. Agoglia, and R. C. Hatfield. 2007. The role of auditor strategy in auditorclient negotiations over proposed financial statement adjustments: The rule of reciprocation. The Accounting Review, 82 (1): 241-263.

Securities and Exchange Commission (SEC). 1999. SEC Staff Accounting Bulletin: No. 99Materiality. SEC 17 CFR Part 211 [Release No. SAB 99].

Schindler, R.M. 1998. Consequences of perceiving oneself as responsible for obtaining a discount. Journal of Consumer Psychology, 7: 371-392 
Shaub, M.K. 2004.Trust as a threat to independence: Emotional trust, auditor-client interdependence, and their impact on professional skepticism. Research on Professional Responsibility and Ethics in Accounting, 9 (2004): 169-188.

Trotman K., A.Wright, and S.Wright. 2005. Auditor negotiations: An examination of the efficacy of intervention methods. The Accounting Review 80 (1): 349-367.

Wright, A., and S. Wright. 1997. An examination of factors affecting the decision to waive audit adjustments. Journal of Accounting, Auditing and Finance (Winter) 12: 15-36. 